\title{
A social work study high-risk behavior among teenagers
}

\author{
Mohammad Reza Iravani*
}

Department of Social Work, Islamic Azad University of Khomeinishahr, Khomeinishahr Branch, Daneshjou Blvd, Iran

\begin{tabular}{|c|c|}
\hline A R T I C L E I N F O & A B S T RA C T \\
\hline $\begin{array}{l}\text { Article history: } \\
\text { Received June 5, } 2011 \\
\text { Received in Revised form } \\
\text { August, 12, } 2011 \\
\text { Accepted } 15 \text { August } 2011 \\
\text { Available online } \\
16 \text { August } 2011 \\
\text { Keywords: } \\
\text { High-risk behavior } \\
\text { Teenager } \\
\text { Crime } \\
\text { Addiction }\end{array}$ & $\begin{array}{l}\text { Teenagers are believed the people who are supposed to build the world's future. High-risk } \\
\text { behaviors such as addiction to drugs, smoking cigarettes, sex, etc. could significantly hurt } \\
\text { teenagers and there must be some supporting programs to reduce these issues as much as } \\
\text { possible. This paper performs an empirical investigation to study different factors influencing } \\
\text { high- risk behavior among teenagers who live in a city of Esfahan, Iran. The proposed study } \\
\text { designs a questionnaire and distributes between two groups of female and male teenagers. The } \\
\text { results indicate that while there is a meaningful relationship between high-risk behaviors and } \\
\text { average teenagers grades among male teenagers there is no meaningful relationship between } \\
\text { high-risk behaviors and teenagers' grades among female students. The results also indicate that } \\
\text { there is a meaningful difference between gender and high-risk behavior. The season of birth for } \\
\text { female and male students is another important factor for having high-risk behaviors. While the } \\
\text { order of birth plays an important role among male students, the order of birth is not an } \\
\text { important factor among female teenagers. Finally, the results indicate that teenagers' parental } \\
\text { financial affordability plays a vital role on both female and male teenagers. }\end{array}$ \\
\hline
\end{tabular}

(C) 2012 Growing Science Ltd. All rights reserved.

\section{Introduction}

Teenagers are our next generation people and the people who are supposed to take care of our world. These people need to learn the necessary skills, get educated and contribute to the world. Teenagers are world's human resources and many high-risk factors such as drug addiction, violence, etc. could hurt these people, significantly. During the past few years, there have been different studies on highrisk behaviors. O'Cathail et al. (2011) performed a study to examine cigarette smoking and risk taking behavior in Irish teenagers. They reported that out of $48.4 \%$ who had smoked tobacco in their lifetime, $15.1 \%$ had used cannabis and claimed that cigarette smokers were more likely to use cannabis than non smokers. The other finding was that cigarette smoking was independently associated with high-risk health behavior and they are more likely to have dysfunctional social relationships.

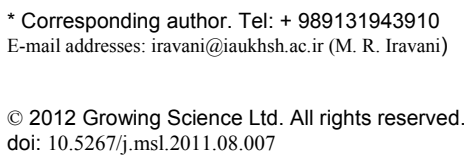


Hedman et al. (2007) investigated influencing factors for smoking cigarette among teenagers and reported that participating in sport activities may delay smoking but it does not necessarily prevent it. Miller (1997) performed an empirical study on family structure, personality, drinking, smoking and illicit drug use on UK teenagers.

Moolchan and Mermelstein (2002) performed a study on ethical challenges of using tobacco among teenagers. They reviewed some of the ethical issues presented in etiologic and clinical treatment research addressing adolescent smoking and reported that context-specific ethical adjustments and alternative perspectives would likely to be required if we intended to overcome procedural difficulties in conducting teen smoking studies. Cornelius et al. (2002) performed a comprehensive study on different drug addictions such as alcohol, tobacco and marijuana among teenagers and reported a 6year follow up of offspring growth effects.

The other issue among teenagers is having sex among them, which could lead to unpredictable consequences such as HIV decease, hepatitis B virus or unwanted pregnancy (Locke et al., 2008). The issue becomes an unfortunate since many of these incidents will remain with the rest of these people's lives. Meheus (2000) studied teenagers' lifestyle and the risk of exposure to hepatitis B virus. Sonenstein (2004) studied the changes on teenagers attitude on sexual relationships. Sonenstein reported that about half of the change is the result of delaying sexual initiation and half is the result of better contraception. Haldre et al. (2007) studied the effects of teenage marriage on poor pregnancy for a ten year period between 1992 to 2002 and reported that an increased risks in neonatal and postneonatal death among younger teenagers of an age of 17 years and less seem to be a result of prematurity. The premature pregnancy would have social consequences as well (Contreras et al., 1995).

The proposed study of this paper study the different factors influencing high- risk behavior among teenagers who live in a city of Esfahan, Iran. The proposed study designs a questionnaire and distribute between two groups of female and male teenagers. This paper is organized as follows. We first present details of our survey and sampling in section 2 and the section 3 presents details of our findings. Finally, concluding remarks are given in the last to summarize the contribution of this paper.

\section{The proposed study}

The city of Isfahan has over 20,000 teenagers who study in high schools and we selected 200 teenagers, 100 male and 100 female, and distributed questionnaire among them. We have adopted a standard questionnaire on high-risk behavior developed by the center of decease prevention in United Stated of America, which contains personal characteristics of participants with 69 questions in Likert (Likert, 1932) scale. The Cronbach Alpha (Cronbach, 1952) was from 0.60 to 0.85, which means the questionnaire yielded valid results. Table 1 summarizes the information of the participants in terms of the average educational performance and the age specification.

\section{Table 1}

Educational performance and age specification of the participants

\begin{tabular}{lccccccc}
\hline Average educational score & Frequency & $\%$ & Accumulate & Age & Frequency & $\%$ & Accumulate \\
\hline Under 10 & 13 & 6.5 & 6.5 & 12 & 9 & 4.5 & 4.5 \\
Between 10 to 15 & 82 & 41 & 47.5 & 13 & 25 & 10.5 & 15.0 \\
Between 15 to 18 & 66 & 33 & 80.5 & 14 & 85 & 42.5 & 57.5 \\
Above 18 & 39 & 19.5 & 100 & 15 & 85 & 42.5 & 100 \\
Sum & 200 & 100 & & & & 100 & \\
\hline
\end{tabular}

Table 2 summarizes personal characteristics of the participants in terms of the season they were born and the order they were born, i.e. whether the participant is the first child, second, etc. 
Table 2

Personal characteristics of the participants in terms of the season and the order they were born

\begin{tabular}{lccccccc}
\hline Season & Frequency & $\%$ & Accumulate & Order & Frequency & $\%$ & Accumulate \\
\hline Spring & 40 & 30 & 30 & 1 & 50 & 25 & 25 \\
Summer & 44 & 22 & 52 & 2 & 84 & 42 & 67 \\
Fall & 49 & 24.5 & 76.5 & 3 & 48 & 24 & 91 \\
Winter & 47 & 23.5 & 100 & 4 and more & 18 & 9 & 100 \\
& 200 & 100 & & & & 100 & \\
\hline
\end{tabular}

Table 3 summarizes personal characteristics of the participants in terms of their fathers' job.

Table 3

Personal characteristics of the participants in terms of their parents' jobs

\begin{tabular}{lccccccc}
\hline Father's Job & Freq. & $\%$ & Accumulate & Mother's Job & Freq. & $\%$ & Accumulate \\
\hline Governmental employee & 44 & 22 & 22 & Governmental employee & 14 & 7 & 7 \\
Businessman & 108 & 54 & 76 & Teacher & 74 & 37 & 44 \\
Retired & 38 & 19 & 95 & Home keeper & 112 & 56 & 100 \\
Others & 10 & 5 & 100 & Others & - & - & 100 \\
\hline
\end{tabular}

Table 4 summarizes personal characteristics of the participants in terms of their accommodation and parents' age.

Table 4

Personal characteristics of the participants in terms of accommodation and parents' age

\begin{tabular}{lccccccccccc}
\hline Accommodation & Freq. & $\%$ & $\begin{array}{c}\text { Mother's } \\
\text { Age }\end{array}$ & Freq. & $\%$ & Accumulate & Father's Age & Freq. & $\%$ & Accumulate \\
\hline Apartment & 80 & 40 & Under 30 & 44 & 22 & 22 & Under 30 & 24 & 12 & 12 \\
House & 92 & 46 & $30-40$ & 89 & 44.5 & 66.5 & $30-40$ & 71 & 35.5 & 47.5 \\
Lease & 28 & 14 & $40-50$ & 53 & 26.5 & 93 & $40-50$ & 71 & 35.5 & 83.0 \\
& 200 & 100 & Above 50 & 14 & 7 & 100 & Above 50 & 34 & 17 & 100 \\
\hline
\end{tabular}

In this survey, only five percent of the people's parents who participate in our survey had less than \$350 US income, 47 percent earned between \$350 US to \$550 US, 40 percent had between \$550 to $\$ 900$ US and 8 percent had over $900 \$$ income. Table 5 summarizes personal characteristics of the participants in terms of their parents' educational background.

Table 5

Personal characteristics of the participants in terms of their parents' educational background

\begin{tabular}{|c|c|c|c|c|c|c|}
\hline $\begin{array}{c}\text { Father's years of } \\
\text { educations }\end{array}$ & Freq. & $\%$ & Accumulate & $\begin{array}{l}\text { Mothers' years of } \\
\text { educations }\end{array}$ & $\%$ & Accumulate \\
\hline 0 & 23 & 11.5 & 11.5 & 68 & 34 & 34 \\
\hline 8 & 102 & 51 & 62.5 & 88 & 44 & 78 \\
\hline $12-14$ & 63 & 31.5 & 94 & 39 & 19.5 & 97.5 \\
\hline$>14$ & 12 & 6 & 100 & 5 & 2.5 & 100 \\
\hline
\end{tabular}

Based on the results discussed in this survey we present the details of our survey in the next section.

\section{Results}

In this section, we present details of our survey results for the proposed study of this paper. We have setup nine hypotheses and examine the results based on statistical observations such as t-student and f-student.

\subsection{The relationship between the average academic performance and high-risk behavior}

The first question is to know whether there is any possible relationship between educational performance and high-risk behavior among female and male teenagers. 
3.1.1 There is a relationship between the average academic performance and high-risk behavior among male teenagers.

Table 6

The relationship between average academic performance and high-risk behavior among male teenagers

\begin{tabular}{lcccc}
\hline Score & Average & Standard deviation & F-value & p-value \\
\hline Under 10 & 45.69 & 1.7 & & \\
$10-15$ & 41.17 & 3.9 & 22.57 & 0.001 \\
$15-18$ & 45.51 & 3.1 & & \\
$18-20$ & 48.69 & 2.7 & & \\
\hline
\end{tabular}

As we can observe from Table 6, the statistical test confirms that there is a meaningful relationship (under $p \leq 0.05$ ) between academic performance and high-risk behavior among male teenagers.

\subsubsection{There is a relationship between the average academic performance and high-risk behavior among female teenagers.}

Table 7

The relationship between average academic performance and high-risk behavior among female teenagers

\begin{tabular}{lcccc}
\hline Score & Average & Standard deviation & F-value & p-value \\
\hline Under 10 & - & - & & \\
$10-15$ & 41.65 & 2.91 & 2.5 & 0.087 \\
$15-18$ & 39.92 & 4.73 & & \\
$18-20$ & 41.80 & 3.78 & & \\
\hline
\end{tabular}

As we can observe from Table 7, the statistical test dose not confirm any meaningful relationship (under $p \leq 0.05$ ) between academic performance and high-risk behavior among female teenagers.

\subsubsection{There is a relationship between the average academic performance and high-risk behavior among male teenagers for pairwise comparison of the teenagers.}

One important question is to know whether there is any meaningful relationship between average academic performance and high-risk behavior by making pairwise comparison of four groups mentioned in Table 7 and Table 8 summarizes the details of our comparison.

\section{Table 8}

Pairwise comparisons of academic performance and high-risk behavior among male teenagers

\begin{tabular}{lcc}
\hline Comparison & Mean difference & p-value \\
\hline Under 10 with $10-15$ & 4.52 & 0.001 \\
$10-15$ with $15-18$ & 4.34 & 0.001 \\
$15-18$ with $18-20$ & 3.17 & 0.006 \\
Under 10 with $18-20$ & 3.00 & 0.025 \\
$10-15$ with $18-20$ & 7.52 & 0.001 \\
\hline
\end{tabular}

\subsection{The relationship between gender and high-risk behavior}

As we can see from the results of Table 8, there is a meaningful difference between high-risk behavior and academic performance among pairwise comparisons of different groups for male teenagers.

\subsubsection{There is a relationship between the gender and high-risk behavior among teenagers.}


Table 9

The relationship between gender and high-risk behavior among teenagers

\begin{tabular}{lcccc}
\hline Gender & Average & Standard deviation & t-student & p-value \\
\hline Male & 43.91 & 4.31 & 4.92 & \multirow{2}{*}{0.000} \\
Female & 41.02 & 3.98 & & \\
\hline
\end{tabular}

As we can observe from Table 9, the statistical test confirms that there is a meaningful relationship (under $p \leq 0.05$ ) between gender and high-risk behavior among teenagers.

\subsubsection{There is a relationship between the season of birth and high-risk behavior among male teenagers.}

\section{Table 10}

The relationship between average season of birth and high-risk behavior among male teenagers

\begin{tabular}{lcccc}
\hline Season & Average & Standard deviation & F-value & p-value \\
\hline Spring & 41.46 & 4.58 & & \\
Summer & 42.64 & 3.00 & 12.18 & 0.001 \\
Fall & 46.66 & 3.86 & & \\
Winter & 46.27 & 2.82 & & \\
\hline
\end{tabular}

As we can observe from Table 10, the statistical test confirms that there is a meaningful relationship (under $p \leq 0.05$ ) between the season of birth and high-risk behavior among male teenagers.

\subsubsection{There is a relationship between the season of birth and high-risk behavior among female teenagers.}

\section{Table 11}

The relationship between average season of birth and high-risk behavior among female teenagers

\begin{tabular}{lcccc}
\hline Season & Average & Standard deviation & F-value & p-value \\
\hline Spring & 41.70 & 2.53 & & \\
Summer & 44.18 & 3.91 & 22.96 & 0.001 \\
Fall & 42.60 & 3.61 & & \\
Winter & 37.20 & 2.58 & & \\
\hline
\end{tabular}

As we can observe from Table 11, the statistical test confirms that there is a meaningful relationship (under $p \leq 0.05$ ) between the season of birth and high-risk behavior among female teenagers.

\subsubsection{There is a relationship between the season of birth and high-risk behavior among male teenagers for pairwise comparison of different seasons.}

In this section, we wish to know whether there is any meaningful relationship between season of birth and high-risk behavior by making pairwise comparisons of four seasons. Table 12 summarizes the details of our comparisons and based on the results we can conclude that there is meaningful relationship among pairwise comparison of different seasons and high-risk behavior among male teenagers.

\section{Table 12}

Pairwise comparisons of academic performance and high-risk behavior among male teenagers

\begin{tabular}{lcc}
\hline Comparison & Mean difference & p-value \\
\hline Spring and Fall & 5.2 & 0.001 \\
Spring and Winter & 4.8 & 0.001 \\
Summer and Fall & 4.02 & 0.001 \\
Summer and Winter & 3.63 & 0.002 \\
\hline
\end{tabular}


3.2.5 There is a relationship between the season of birth and high-risk behavior among female teenagers for pairwise comparison of different seasons.

In this section, we wish to know whether there is any meaningful relationship between season of birth and high-risk behavior by making pairwise comparisons of four seasons. Table 13 summarizes the details of our comparisons and based on the results we can conclude that there is meaningful relationship among pairwise comparison of different seasons and high-risk behavior among female teenagers.

Table 13

Pairwise comparisons of academic performance and high-risk behavior among female teenagers

\begin{tabular}{lcc}
\hline Comparison & Mean difference & $\mathrm{p}$-value \\
\hline Spring and Fall & 2.48 & 0.001 \\
Spring and Winter & 4.49 & 0.001 \\
Summer and Fall & 6.98 & 0.001 \\
Summer and Winter & 5.39 & 0.001 \\
\hline
\end{tabular}

\subsection{The relationship between the order of birth and high-risk behavior}

In this section, we study the relationship between the order of birth and high-risk behavior. In other words we want to know whether it makes a difference when a person is the first member of a family, the second member of a family, etc.

\subsubsection{There is meaningful relationship between the order of birth and high-risk behavior among male teenagers}

The first part of the study of this section focuses on the relationship between the order of birth and high-risk behavior among male teenagers. Table 14 summarizes the details of our comparisons.

\section{Table 14}

The relationship between average order of birthday and high-risk behavior among male teenagers

\begin{tabular}{lcccc}
\hline Order & Average & Standard deviation & F-value & p-value \\
\hline First & 40.83 & 5.84 & & \\
Second & 43.58 & 2.72 & 6.23 & 0.001 \\
Third & 44.63 & 4.27 & & \\
Fourth and more & 46.38 & 3.31 & & \\
\hline
\end{tabular}

As we can observe from Table 14, the statistical test confirms that there is a meaningful relationship (under $p \leq 0.05$ ) between the order of birth and high-risk behavior among male teenagers.

\subsubsection{There is meaningful relationship between the order of birth and high-risk behavior among female teenagers}

The second part of the study of this section focuses on the relationship between the order of birth and high-risk behavior among female teenagers. Table 15 summarizes the details of our comparisons.

Table 15

The relationship between average order of birthday and high-risk behavior among female teenagers

\begin{tabular}{lcccc}
\hline Order & Average & Standard deviation & F-value & p-value \\
\hline First & 40.96 & 2.70 & & \\
Second & 40.74 & 3.95 & 0.548 & 0.580 \\
Third & 41.88 & 5.76 & & \\
Fourth and more & - & - & & \\
\hline
\end{tabular}


As we can observe from Table 15, the statistical test does not confirm that there is any meaningful relationship (under $p \leq 0.05$ ) between the order of birth and high-risk behavior among female teenagers.

\subsection{The relationship between the family income and high-risk behavior}

\subsubsection{There is meaningful relationship between the family income and high-risk behavior among male teenagers}

The first part of the study of this section focuses on the relationship between the family income and high-risk behavior among male teenagers. Table 16 summarizes the details of our comparisons.

\section{Table 16}

The relationship between average family income and high-risk behavior among male teenagers

\begin{tabular}{lcccc}
\hline Income & Average & Standard deviation & F-value & p-value \\
\hline Under $\$ 350$ US & - & - & & \\
$\$ 350-\$ 550$ & 42.26 & 4.78 & 5.66 & 0.005 \\
\$550-\$900 & 44.91 & 3.78 & & \\
More than $\$ 900$ & 45.70 & 2.21 & & \\
\hline
\end{tabular}

As we can observe from Table 16, the statistical test confirms that there is a meaningful relationship (under $p \leq 0.05$ ) between the order of birth and high-risk behavior among male teenagers.

\subsubsection{There is meaningful relationship between the family income and high-risk behavior among female teenagers}

The first part of the study of this section focuses on the relationship between the family income and high-risk behavior among female teenagers. Table 17 summarizes the details of our comparisons.

Table 16

The relationship between average family income and high-risk behavior among female teenagers

\begin{tabular}{lcccc}
\hline Income & Average & Standard deviation & F-value & p-value \\
\hline Under $\$ 350$ US & 41.20 & 5.28 & & \\
$\$ 350-\$ 550$ & 39.92 & 3.11 & 3.77 & 0.021 \\
$\$ 550-\$ 900$ & 42.61 & 4.65 & & \\
More than $\$ 900$ & 42.16 & 1.94 & & \\
\hline
\end{tabular}

As we can observe from Table 17, the statistical test confirms that there is a meaningful relationship (under $p \leq 0.05$ ) between the order of birth and high-risk behavior among female teenagers.

\section{Conclusion}

In this paper, we have investigated different factors influencing high-risk behavior among teenagers who live in a city of Esfahan, Iran. The proposed study designed a questionnaire and distributed between two groups of female and male teenagers each with a sample size of 100 teenagers. The results indicated that while there is a meaningful relationship between high-risk behaviors and average high school marks among male students, there is no meaningful relationship between highrisk behaviors and high school grades among female students. The results also indicated that there was a meaningful difference between gender and high-risk behavior. The season of birth for female and male students is another important factor for having high-risk behaviors. While the order of birth plays an important role among male students, the order of birth was not considered as an important 
factor among female teenagers. Finally, the results indicate that teenagers' parental financial affordability plays a vital role on both female and male teenagers.

\section{Acknowledgment}

The present study was financially supported by a grant awarded by Islamic Azad University and the author would like to thank the officials for the financial support.

\section{References}

Contreras, J. M., Rhodes, J. E., \& Mangelsdorf, S. C. (1995). Pregnant African American teenagers' expectations of their infants' temperament: Individual and social network influences. Journal of Applied Developmental Psychology, 16(2), 283-295.

Cornelius, M.D., Goldschmidt, L., Day, N.L., \& Larkby, C. (2002). Alcohol, tobacco and marijuana use among pregnant teenagers: 6-year follow-up of offspring growth effects. Neurotoxicology and Teratology, 24(6), 703-710.

Cronbach, L. J. (1951). Coefficient alpha and the internal structure of tests. Psychometrika, 16(3), 297-334.

Locke, T.F., \& Newcomb, M.D. (2008). Correlates and predictors of HIV risk among inner-city African American female teenagers. Health Psychology, 27(3), 337-348.

Likert, R. (1932). A Technique for the Measurement of Attitudes. Archives of Psychology, 140, 1-55.

Hedman, L., Bjerg-Bäcklund, A., Perzanowski, M., Sundberg, S., \& Rönmark, E. (2007). Factors related to tobacco use among teenagers. Respiratory Medicine, 101(3), 496-502.

Haldre, K., Rahu, K., Karro, H., \& Rahu, M. (2007). Is a poor pregnancy outcome related to young maternal age? A study of teenagers in Estonia during the period of major socio-economic changes (from 1992 to 2002). European Journal of Obstetrics \& Gynecology and Reproductive Biology, 131(1), 45-51.

Miller, P. (1997). Family structure, personality, drinking, smoking and illicit drug use: a study of UK teenagers. Drug and Alcohol Dependence, 45(1-2), 121-129.

Moolchan, E. T., \& Mermelstein, R. (2002). Research on tobacco use among teenagers: ethical challenges. Journal of Adolescent Health, 30(6), 409-417.

Meheus, A. (2000). Teenagers' lifestyle and the risk of exposure to hepatitis B virus. Vaccine, 18(1), 26-29.

O'Cathail, S.M., O'Connell, O.J., Long, N., Morgan, M., Eustace, J.A., Plant, B.J., \& Hourihane, J.O'.B. (2011). Association of cigarette smoking with drug use and risk taking behaviour in Irish teenagers. Addictive Behaviors, 36(5), 547-550.

Sonenstein, F.L. (2004). What teenagers are doing right: changes in sexual behavior over the past decade. Journal of Adolescent Health, 35(2), 77-78. 